\title{
Early primary Kawashima operation combined with direct hepatic vein-to-azygos vein connection: A new logical approach
}

\author{
Antonio Amodeo, MD, ${ }^{a}$ Duccio Di Carlo, MD, ${ }^{a}$ Mauro Grigioni, Eng, ${ }^{\text {b }}$ \\ Marcello De Santis, MD, ${ }^{\mathrm{c}}$ and Roberto M. Di Donato, MD, ${ }^{\mathrm{a}}$ Rome, Italy
}

$\mathrm{P}$

atients with single ventricle, left isomerism, and azygos continuation of the inferior vena cava usually undergo a staged cardiac repair comprising a total bidirectional cavopulmonary anastomosis with the exclusion of the hepatic venous return (Kawashima operation) during childhood followed by a complementary hepatic vein-to-pulmonary artery connection (Fontan completion) 2 to 3 years later. The latter step can effectively counteract the progressive cyanosis resulting from both systemic venous collaterals emptying into the low-pressure hepatic venous compartment and pulmonary arteriovenous malformations related to lack of a putative hepatic or splanchnic factor. However, both the intracardiac and the extracardiac conventional pathways for diverting the hepatic venous return to the pulmonary circulation are highly predisposed toward thrombosis. ${ }^{1}$ This is caused by an intrinsic tendency for deep vein thromboses typical in patients with interrupted inferior vena cava, sometimes associated with hypercoagulable state secondary to factor XII deficiency or heterozygous presence of factor $\mathrm{V}$ Leiden mutation, ${ }^{2}$ and by the relative low flow from the hepatic veins.

Focusing on the issue of low flow, we hypothesized that the hepatic venous return ( $20 \%$ of total venous return) should preferably merge with the azygos vein and follow its stream, rather than struggling its way up to the pulmonary arteries against the overwhelming gravitational flow from the superior vena cava (carrying $80 \%$ of the total venous return).

\section{Clinical Summary}

In September 2003, we performed primary total cavopulmonary anastomosis (Kawashima operation) in combination with direct hepatic vein-to-azygos vein connection in a 2-year-old girl (9 $\mathrm{kg}$ body weight) with the following diagnosis: $\{\mathrm{A}, \mathrm{D}, \mathrm{L}\} \mathrm{dex}-$ trocardia, crisscross heart, double-outlet hypoplastic right ventricle, pulmonary stenosis, atrial septal defect, and azygos continuation of the inferior vena cava. Her anatomy had not been

From Division of Pediatric Cardiac Surgery, Bambino Gesù Hospital,a Division of Cardiovascular Bioengineering, Istituto Superiore di Sanità, and Department of Radiology, S. Andrea Hospital, ${ }^{\mathrm{c}}$ Rome, Italy.

Received for publication Aug 14, 2004; accepted for publication Aug 19, 2004.

Address for reprints: Antonio Amodeo, MD, Dipartimento Medico Chirurgico di Cardiologia Pediatrica, Ospedale Bambino Gesù, Piazzale S. Onofrio 4, Rome 00165, Italy (E-mail: antonioamodeo@yahoo.it).

J Thorac Cardiovasc Surg 2005;129:949-50

$0022-5223 / \$ 30.00$

Copyright $\odot 2005$ by The American Association for Thoracic Surgery doi:10.1016/j.jtcvs.2004.08.032 surgically altered, and she had severe cyanosis. The operation was performed with the

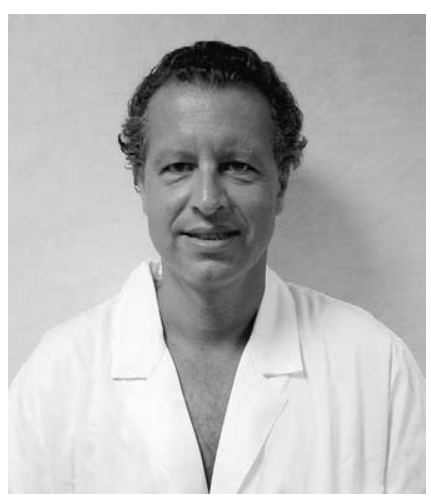

Dr Amodeo heart beating, except for a short period of deep hypothermia and circulatory arrest during the hepatic vein-to-azygos vein anastomosis. Technically, a large cuff of right atrium was resected around the hepatic veins and shaped in a tubular fashion to ease the reach of the azygos vein and relieve any tension from the anastomosis. The postoperative period was uneventful. A magnetic resonance imaging study showed a geometrically perfect hepatic vein-to-azygos venous confluence (Figure 1), and there was no gradient seen on Doppler echocardiographic examination (Figure 2). The patient is doing well 10 months after this operation.

\section{Discussion}

Second-stage anastomosis of the hepatic veins to the azygos vein (after first-stage Kawashima operation) was first described by

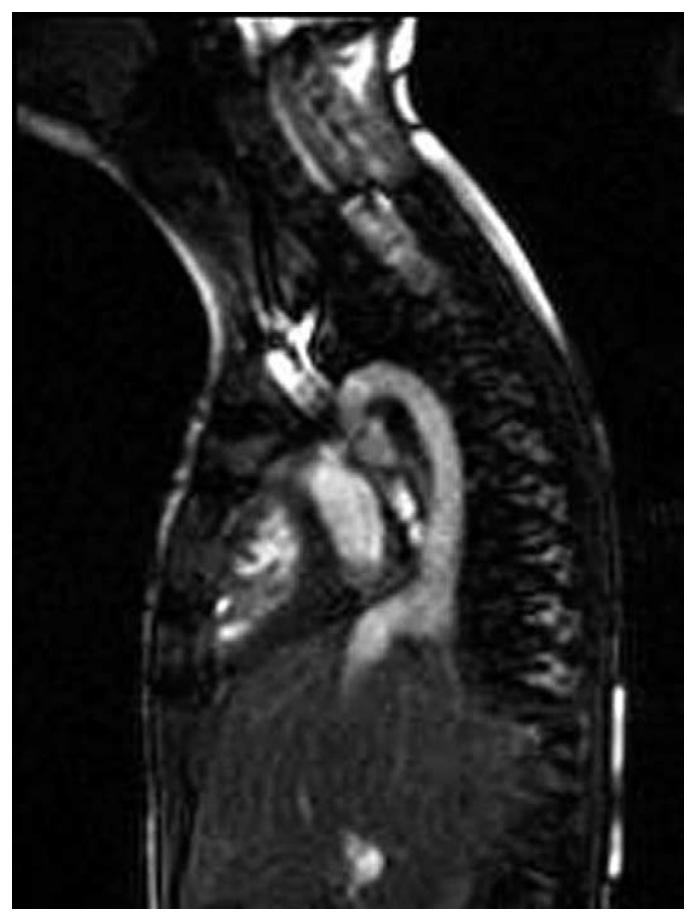

Figure 1. Magnetic resonance imaging study showing geometrically perfect hepatic-to-azygos venous confluence. 


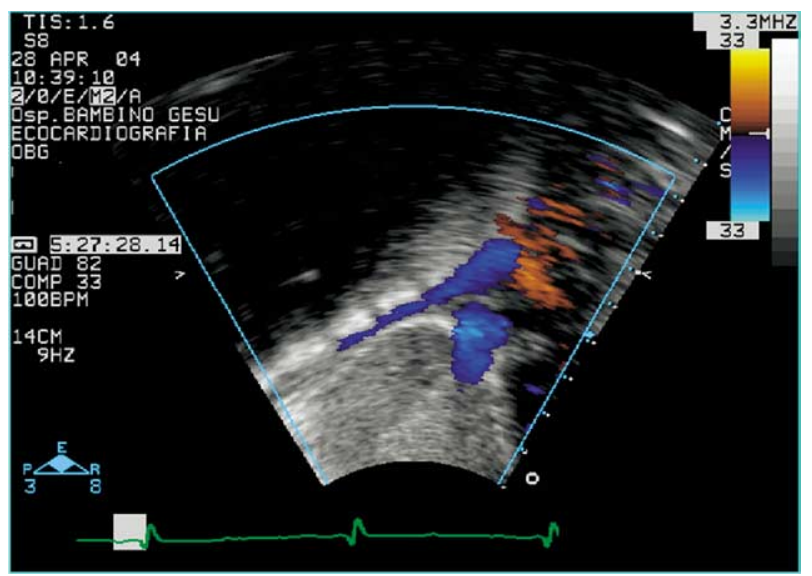

Figure 2. Doppler echocardiogram showing no gradient.

Baskett and colleagues ${ }^{3}$ for treatment of pulmonary arteriovenous fistulas in a 14-year-old patient. Subsequently, Kaneko and associates ${ }^{4}$ and Steinberg and coworkers ${ }^{5}$ published modifications of the technique, for management of collateral circulation to the hepatic veins in an 8-year-old boy and pulmonary arteriovenous malformations in a 16-year-old boy, respectively. Several issues have been raised in support of this approach. It allows for balanced distribution of hepatic venous blood to the pulmonary arteries, eliminates any need for prosthetic tube grafts, minimizes arrhythmogenic atrial incisions, and does not require extensive mobilization of scar tissue, particularly around the pulmonary arteries. ${ }^{3-5}$ Circulatory arrest is a potential drawback, but it is technically avoidable. $^{4,5}$
This is the first reported case of primary Kawashima operation combined with a direct anastomosis of the hepatic veins to the azygos vein, and demonstrates the feasibility of this approach even at an early stage of life. We have preliminary experimental evidence that this operation provides a hydrodynamically more efficient recruitment of the hepatic venous return to the pulmonary circulation than does the classic end-to-end connection with conduit interposition (unpublished data). Longer follow-up is necessary to prove the validity of this approach. We believe that it can minimize the risk of thromboembolic accident in patients with single ventricle, left isomerism, and azygos continuation of the inferior vena cava, although because of their intrinsically hypercoagulability state, such patients should probably always continue to receive oral anticoagulants.

\section{References}

1. Konstantinov IE, Puga FJ, Alexi-Meskishvili VV. Thrombosis of intracardiac or extracardiac conduits after modified Fontan operation in patients with azygous continuation of the inferior vena cava. Ann Thorac Surg. 2001;7:1641-4.

2. Mouton WG, Zehnder T. Deep vein thrombosis in azygos continuation. Eur J Vasc Endovasc Surg. 2003;25:90-2.

3. Baskett RJ, Ross DB, Warren AE, Sharratt GP, Murphy DA. Hepatic vein to the azygous vein anastomosis for pulmonary arteriovenous fistulae. Ann Thorac Surg. 1999;68:232-3.

4. Kaneko Y, Murakami A, Miyamoto T, Takamoto S. Hepatic vein-toazygos vein connection in a patient with interrupted inferior vena cava. Eur J Cardiothorac Surg. 2002;21:582-4.

5. Steinberg J, Alfieris GM, Brandt B 3rd, Smith F, Byrum CJ, Fink GW, et al. New approach to the surgical management of pulmonary arteriovenous malformations after cavopulmonary anastomosis. Ann Thorac Surg. 2003;75:1640-2. 